\title{
Computational pipeline for genomic epidemiology surveillance of pathogenic bacteria
}

\author{
Andrey Shelenkov \\ Central Research Institute of Epidemiology \\ Moscow, Russia \\ 0000-0002-7409-077X \\ Yulia Mikhaylova \\ Central Research Institute of Epidemiology \\ Moscow, Russia \\ mihailova@cmd.su
}

\author{
Yurii Yanushevich \\ Central Research Institute of Epidemiology \\ Moscow, Russia \\ 0000-0001-9061-752X \\ Vasiliy Akimkin \\ Central Research Institute of Epidemiology \\ Moscow, Russia \\ 0000-0003-4228-9044
}

\begin{abstract}
Due to rapid development of the second and third generations of high-throughput sequencing systems, the number of available pathogenic bacteria genomes has increased dramatically in last 10 years and reached 60,000 in 2019 . Novel software and computational pipelines are required to process such a huge amount of data in order to derive useful information from it. Here we present a pipeline combining various existing bacterial typing and annotation tools to create an easy-to-use and flexible environment for investigating the whole genomes of pathogenic bacteria obtained by high-throughput sequencing. The pipeline includes multi-locus sequence typing, antibiotic resistance and virulence genes' annotation, plasmid detection and typing, and various other useful features.
\end{abstract}

Keywords - annotation pipeline, bacterial genome analysis, NGS, antibiotic resistance, genomic epidemiology

\section{Introduction}

The development of second- and third-generation sequencing technologies (NGS) has dramatically simplified and greatly lowered the cost of obtaining the whole genomes, especially, bacterial ones. In the field of clinical bacteriology, rapid and reproducible identification, typing and annotation of bacterial pathogens is vitally important, and, thus, NGS slightly becomes a commonly used practice for outbreak and infection transmission investigation. Although many computational pipelines for bacterial genome annotation are available, currently the need still exists for flexible tools that can be routinely used in clinical and epidemiological investigations. We have developed such a pipeline for typing and annotation of clinical and food poisoning bacterial pathogens. It can be used for scientific purposes in the emerging field of bacterial genomic epidemiology that combines the use of molecular biology, epidemiology and bioinformatics techniques and procedures for infectious disease surveillance and outbreak investigations.

\section{Matherials and Methods}

To achieve the goals set above, we have developed a set of custom scripts for seamless integration of various software tools within Linux ecosystem. The input data should include genome sequences (complete chromosomes or assembled contigs) in FASTA format. Batch processing of multiple genomes of the same or various bacterial species is possible; however, species name should be set for each group of organisms separately. First step of the pipeline includes running BLAST on ' $\mathrm{nt}$ ' or other similar database locally to verify that genomic sequence really belongs to the organism of interest. If it does not, all downstream species-specific tests are skipped. Mixtures of different organisms are also reported.
Then MLST-typing [1] is performed if the MLST scheme is available for the species under study. After that, ResFinder [2] is called to check for the presence of known acquired antibiotic-resistance genes in genomic sequence. This search is not species-specific, so it can be performed for any bacteria. Next steps include searching for known virulence genes with VirulenceFinder [3] and detecting plasmids in input sequence using PlasmidFinder [4]. These programs rely on the databases that store the data only for some bacterial families. If the data for the current species is not available, these steps will be excluded from the pipeline.

Then additional typing is performed when it is available for the given species. For example, the typing schemes based on capsular (K, or KL) loci and oligosaccharide (O) loci are available for Klebsiella pneumoniae and Acinetobacter baumannii, SPA-typing scheme based on the sequence of a polymorphic variable number tandem repeat is used for Staphylococcus aureus etc.

Finally, the results obtained by the programs mentioned above are summarized and presented in concise tabular form for each defined group of bacteria.

Some additional processing steps including phylogenetic tree building are also available as optional procedures.

It is worth mentioning that the pipeline can be easily updated by adding new antibiotic resistance genes, virulence genes or plasmid sequences for various organisms to the existing local databases. These updates are as simple as adding or editing text files.

\section{Results}

The pipeline developed is routinely used in our group for rapid annotation of newly sequenced clinical bacterial isolates, mainly belonging to ESKAPE pathogen group and food poisoning pathogens. The combination of various typing schemes (MLST, cgMLST, KL, O) allows narrowing isolate classification and facilitates the investigations of antimicrobial resistance spreading within the given healthcare unit, hospital or even at the country or international level.

The example of main output file in tabular format is presented in the Table 1. 
TABLE 1 - EXEMPLARY PIPELINE OUTPUT

\begin{tabular}{|c|c|c|c|c|c|c|}
\hline $\begin{array}{c}\text { Sam } \\
\text { ple } \\
\text { ID }\end{array}$ & Species & MLST & $\begin{array}{c}\text { AR } \\
\text { genes }^{a}\end{array}$ & $\mathbf{A} \mathbf{R}^{\mathbf{a}}$ & $\begin{array}{l}\text { Virulenc } \\
\text { e genes }\end{array}$ & $\begin{array}{l}\text { KL- } \\
\text { type }\end{array}$ \\
\hline $\mathrm{N}_{49}$ & $\begin{array}{l}\text { Klebsiella } \\
\text { pneumoniae }\end{array}$ & ST25 & $\begin{array}{c}\text { aac(3)- } \\
\text { IIa, } \\
\text { aadA1, } \\
\text { strA; } \\
\text { bla- } \\
\text { OXA- } \\
48\end{array}$ & $\begin{array}{c}\text { Amino } \\
\text { glycosi } \\
\text { de; } \\
\text { Beta- } \\
\text { lactam }\end{array}$ & $\begin{array}{l}\text { mrkA2, } \\
\text { mrkB2 }\end{array}$ & KL2 \\
\hline $\begin{array}{c}\mathrm{N} 2- \\
56\end{array}$ & $\begin{array}{c}\text { Klebsiella } \\
\text { pneumoniae }\end{array}$ & ST395 & fosA & $\begin{array}{c}\text { Fosfom } \\
\text { ycin }\end{array}$ & $\begin{array}{l}\text { fyuA_2, } \\
\text { irp1285 }\end{array}$ & KL61 \\
\hline
\end{tabular}

c. In 'AR genes' and 'AR' columns ';' is used as a separator between antibiotic groups

\section{Conclusions}

We have developed a user-friendly computational pipeline for typing and annotation of pathogenic bacteria genomes including antibiotic resistance prediction, MLST-based sequence type assignment, typing based on capsular and oligosaccharide loci, virulence gene finding and plasmid revealing, and other useful features including phylogenetic tree building. It can become a useful tool for epidemiological and genomic studies of newly sequenced bacterial pathogens. The pipeline can be updated or expanded without substantial efforts.

\section{REFERENCES}

[1] M.V. Larsen, S. Cosentino, S. Rasmussen, "Multilocus Sequence Typing of Total-Genome-Sequenced Bacteria", J. Clin. Microbiol., vol. 50, pp. 1355-1361, 2012.

[2] E. Zankari, H. Hasman, S. Cosentino et al., "Identification of acquired antimicrobial resistance genes", J Antimicrob. Chemother., vol. 67, pp. 2640-2644, 2012.

[3] K.G. Joensen, F. Scheutz, O. Lund et al, "Real-time whole-genome sequencing for routine typing, surveillance, and outbreak detection of verotoxigenic Escherichia coli”, J. Clin. Microbiol., vol. 52, pp.15011510, 2014.

[4] A. Carattoli, E. Zankari, A. Garcia-Fernandez et al. "In silico detection and typing of plasmids using PlasmidFinder and plasmid multilocus sequence typing", Antimicrob. Agents Chemother., vol. 58, pp. 38953903, 2014 